\title{
Une stèle funéraire de Palmyre
}

\section{Daniel Bornemann}

\section{(2) OpenEdition}

Journals

Édition électronique

URL : http://journals.openedition.org/rbnu/1388

DOI : $10.4000 /$ rbnu. 1388

ISSN : 2679-6104

\section{Éditeur}

Bibliothèque nationale et universitaire de Strasbourg

\section{Édition imprimée}

Date de publication : 1 novembre 2015

Pagination : 70-71

ISBN : 9782859230616

ISSN : 2109-2761

\section{Référence électronique}

Daniel Bornemann, "Une stèle funéraire de Palmyre », La Revue de la BNU [En ligne], 12 | 2015, mis en ligne le 01 mars 2020, consulté le 11 décembre 2020. URL : http://journals.openedition.org/rbnu/1388 ; DOI : https://doi.org/10.4000/rbnu.1388

\section{c) (i)(2)}

La Revue de la BNU est mise à disposition selon les termes de la Licence Creative Commons Attribution - Pas d'Utilisation Commerciale - Partage dans les Mêmes Conditions 4.0 International. 


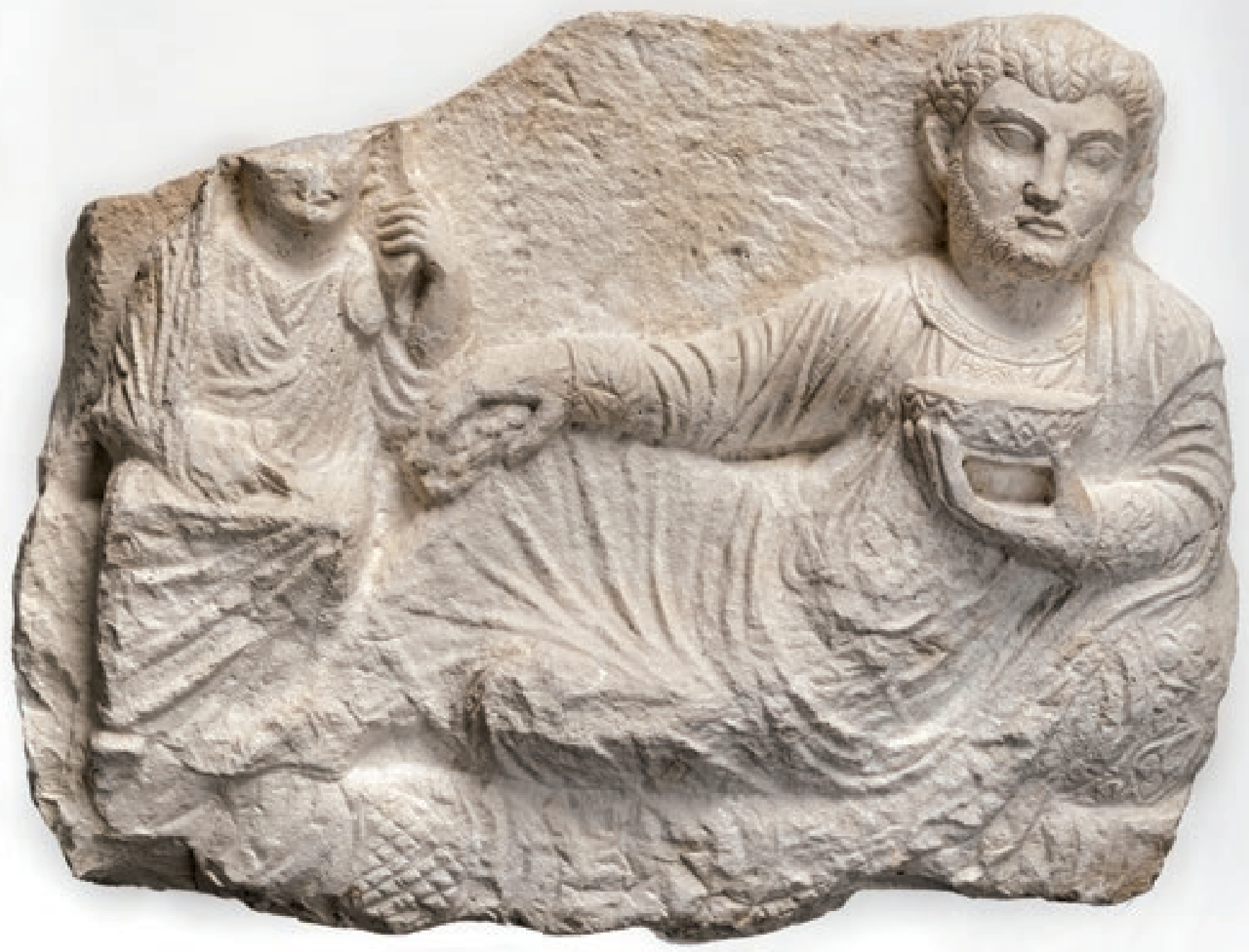




\section{UNE STÈLE FUNÉRAIRE DE PALMYRE}

$\hat{\Lambda}$

l'heure où le destin des ruines et des restes archéologiques de Palmyre bascule vers une nouvelle phase de destruction, le moment est venu de rappeler l'existence, au sein des collections antiques de la BNU, d'une série de monuments et d'inscriptions en provenance de cette cité. En effet, lors d'un de ses voyages en Orient, en août 1887, Julius Euting a rapporté de Palmyre pas moins de six sculptures représentant des personnages, en bas-relief ou en ronde bosse, deux autels votifs avec inscriptions, trois fragments d'inscriptions sans figurations et d'autres objets plus petits, comme 10 tessères et 3 médaillons de terre cuite. L'une des sculptures en bas-relief a été restaurée au cours du printemps 2015 par l'atelier Péquignot, restauration qui a consisté en un nettoyage de surface du marbre blanc et en la consolidation de l'existant, aux endroits où la pierre présentait des fissures.

Cette stèle semble à première vue ne présenter aucune inscription ; on y observe la représentation d'un homme portant une barbe, installé sur un lit de repos, tenant une patène de sa main gauche alors que sa main droite repose sur son genou droit. À sa droite figure une femme assise de face, dont la tête manque en grande partie, mais dont on distingue le geste : elle écarte son voile de sa main gauche tandis que sa droite repose sur ses genoux.

À l'époque, les yeux exercés de l'épigraphiste Euting ont repéré trois lettres tracées entre les deux têtes des personnages. À partir de trois lettres, le savant restitua de manière hypothétique l'anthroponyme Malôkâ. Il y vit en effet ce qui en transcription latine donnait : $[\mathrm{m}] 1[\mathrm{w}] \mathrm{k}$, soit avec vocalisation restituée Malôkâ.

Cette inscription, difficile à distinguer, a été publiée dans le Corpus des inscriptions sémitiques ${ }^{1}$. Cet ouvrage, entièrement rédigé en latin, en donne la description suivante :
Lapis mutilus, altus $\mathrm{o}^{\mathrm{m}}, 55$, latus $\mathrm{o}^{\mathrm{m}}, 40$, anaglypho ornatus : dextrorsum, vir lecto recumbens, patenam manu sinistra tenens ; sinistrorsum, mulier cathedra sedens, capitis velum manu sinistra amovens. Monumentum Palmyrae repertum Argentoratum adportavit Euting ; ad ipsum expressam imaginem tabula damus.

Corroso lapide, tituli inter capita exarati vestigia vix supersunt, e quibus nomen unum cum probabilitate eruere licet, nempe $:$ :

L’inscription a plus récemment été rééditée par $D$. R. Hillers et E. Cussini (Palmyrene Aramaic Texts, Baltimore, 1996), sous le $n^{\circ}$ o980 (page 157).

La datation de cette sculpture est délicate, mais elle serait à situer vraisemblablement au $3^{\mathrm{e}}$ siècle de notre ère.

C'est en août 1883 qu'Euting parcourut la région de Palmyre et releva nombre d'inscriptions par divers procédés. On peut lire ses carnets relatant ce voyage, d'ailleurs mouvementé, sur le site de la Bibliothèque universitaire de Tübingen, qui les conserve et qui les a numérisés ${ }^{2}$. Nous apprenons par les archives de la BNU que cinq caisses ont transité de Beyrouth jusqu'à Kehl, contenant les achats et les découvertes faits par Euting durant ce long voyage. Il affirme que le contenu a été pillé et est arrivé de manière incomplète, le 23 décembre 1885 seulement.

\section{Daniel Bornemann}

\footnotetext{
Notes

1 - Corpus inscriptionum semiticarum ab academia inscriptionum et litterarum humaniorum conditum atque digestum. Pars secunda : inscriptiones aramaicas continens. Tomus III. Paris : Imprimerie nationale, 1926. Pour l'objet qui nous concerne, voir p. $477, \mathrm{n}^{\circ} 4619$ et tab. XXXIX. Notons qu'Euting a fait une erreur, confondant la largeur avec la hauteur.

2 - Sous la cote Md 676-19, on trouve le carnet qui relate cette expédition. Adresse permanente : http://idb.ub.uni-tuebingen.de/diglit/Md676-19.
} 